\title{
Does Exposure to Multicultural Experience Enhance All Individuals' Creative Problem-Solving Ability?
}

\author{
Mehrdad F. Falavarjani (Corresponding author) \\ Department of Social Psychology, Universiti Putra Malaysia, Malaysia \\ E-mail: fazeli.mehrdad@gmail.com
}

Forouzan Irandoust

Department of Psychology, University of Isfahan, Iran

Received: May 4, 2017 Accepted: May 25, 2017 Published: August 10, 2017

doi:10.5296/ijssr.v5i2.11173ＵRL: http://dx.doi.org/10.5296/ijssr.v5i2.11173

\begin{abstract}
Today's diverse community often includes culturally rich environments that contain cues pertaining to more than one cultures. These cultural cues can shape cognitive processes, such as creativity. This study aims to investigate the interactive effects of Openness to Experience, Extroversion and Multicultural Experience (including the real and desired experiences) on creative problem-solving ability using the quantitative method on a diverse sample of international students $(N=102)$. The findings indicate that the interactive effect of extensive multicultural experience and Openness to Experience predict the creative solution. It means multicultural experience is beneficial for individuals to foster creative ability when they are highly open to experience, whereas among those who are not open, more extensive multicultural experience do not lead to enhancement of creating the correct solution. Furthermore, this interaction term was not pronounced among the extroverted individuals. Implications of these findings for promoting creativity in learning environments are discussed.
\end{abstract}

Keywords: Multicultural Experience, Openness to Experience, Extroversion, Personality Traits, Creativity

\section{Background}

The potential to create novel ideas to solve everyday problems is an important component of creativity (Amabile, 1996; Leung \& Chiu, 2008; Sternberg \& O'Hara, 1999). There is evidence highlighting that new cultural exposure in association with a period of reflection and transformation will leave individuals with an improved ability to engender novel ideas 
(Leung, Maddux, Galinsky, \& Chiu, 2008). According to Leung et al. (2008), when individuals hold onto some available knowledge of their own culture and resist rejecting new ideas from other cultures, the ability to create new ideas may be hampered (Leung \& Chiu, 2008). Thus, it is important to investigate whether exposure to multicultural experience can decline individuals' reliance on their own cultural knowledge and consequently foster their creativity (Chiu \& Hong, 2005; Leung \& Chiu, 2008).

The reason to accept that multicultural experience can enhance individuals' creativity for those with higher levels of Openness to Experience is that open to new ideas from other different cultures may lead to retrieving memory from less prototypical ideas and generate unconventional uses of an ordinary object (Chen \& Chiu, 2006; Leung \& Chiu, 2008). In contrast, exposure to a new culture is argued to be overwhelming, shocking, and even threatening for those with lower levels of Openness to Experience. To manage the negative effect of new experiences, these individuals would rely back on conventional ideas in their own culture (Chao, Chen, Roisman, \& Hong, 2007). Consequently, it may result in a greater tendency to retrieve from memory prototypical in a conceptual domain, and hence generate less creative ideas (Leung \& Chiu, 2008).

Despite the fact that Leung and Chiu (2008) showed the extensive multicultural experience is positively associated with creativity among individuals with high levels of Openness, the association with another main personality trait, Extroversion, remained unknown. Extroversion has shown to associate with creativity (for reviews, see, Feist, 1998) as well as the new cultural experience (Wilt \& Revelle, 2008). Therefore, in line with the previous study, the current research put a step further to assess the interactive effect of multicultural experience and two aspects of Big Five Personality Traits, Openness to Experience and Extroversion, on the creative problem-solving ability.

\subsection{Multicultural Experience and Creativity}

Some ideas are relatively more acceptable in a culture than in others (Chen \& Chiu, 2006). Thus, living in a foreign culture for the most parts is perceived as invaluable opportunities to experience new cultural knowledge and information that are prevalent in the other culture, but unfamiliar to one's own culture. This knowledge and experience could be recruited and synthesized to find new solutions in problem-solving tasks. In fact, some current studies demonstrated potential positive impacts of multicultural experience on the enhancement of the problem-solving ability (Benet-Martínez, Lee, \& Leu, 2006; Maddux, Adam, \& Galinsky, 2010).

Originating from the previous study by Leung, Maddux, Galinsky, and Chiu (2008), multicultural experience benefits the individuals in terms of enhancement of creative ability with a number of factors. Firstly, this group has the tendency to have richer conceptual structures because they obtained knowledge from more than one cultures and this increases their cognitive ability to analyze more complex information processing styles, resulting from interacting with unfamiliar ideas (Chiu \& Hong, 2005; Hong, Morris, Chiu, \& Benet-Martinez, 2000). Secondly, the experience of intercultural contact may enhance the individuals' psychological readiness to accept inaccessibly novel ideas and in turn ease the 
recruitment of unfamiliar ideas for creative problem-solving (Leung \& Chiu, 2008). Finally, constant challenges between new ideas of a new culture and conventional ones of individuals' own culture may generate new insights on the interrelations between these foreign and home cultural knowledge, and consequently, promote the combinations of different ideas from various cultures as the new one (Chiu \& Hong, 2005). In sum, when new and unconventional ideas combine, multicultural experience naturally becomes receptive, the memory-knowledge may spontaneously access unfamiliar ideas which are inaccessible in the heritage culture, and, as result, engender creative ideas. However, it is worth asking "does the exposure to multicultural experience foster all individuals' creativity?"

\subsection{Openness to Experience, Multicultural Experience, and Creativity}

Openness to Experience has shown as a personality aspect most closely associated with creativity (Feist, 1998; McCrae \& Costa, 1987, 2008). According to McCrae and Costa (2008), three possible reasons are taken into account for the association. Firstly, these individuals may be more fascinated with the open-ended, creative, problem-solving tasks, and may simply score higher on such tasks. Secondly, they may have developed cognitive skills associated with creative, divergent thinking, namely flexibility and fluidity of thought. Finally, these individuals have an interest in sensation seeking and more varied experiences, and unafraid of recruiting unconventional ways to deal with problems at hand (Leung \& Chiu, 2008). In the other words, appreciative of novel ideas and new experience, receptive to a variety of perspectives and thoughts, and unafraid of applying new ways to deal with a wide range of thoughts, feelings, and problem-solving tasks benefit these individuals in order to generate novel and useful solutions or ideas (Costa \& McCrae, 1992; Feist, 1998; McCrae \& Costa, 1997). In fact, not only do the open-minded individuals incline more to learn from new cultural experience, and consequently turn into creative beings, they also benefit from multicultural learning once they have the opportunities of learning in diverse contexts (Leung $\&$ Chiu, 2008). Therefore, it can be predicted that among individuals who are open to experience, the extent of multicultural experience would be positively associated with higher level of creative problem-solving ability.

In contrast, according to Hong, Wan, No, and Chiu (2007), people who are exposed to multicultural experience often reports the feelings of ambivalence, threaten and even culture shock. Leung and Chiu (2008) strongly argue that this negative reaction may take place among those who are not open to experience. For instance, they reported that when close-minded Chinese students were given pictures of American culture (vs. control images), they reject adapting American practices and instead strongly holding onto the Chinese conflict strategies. But, when open-minded Chinese students were presented with the same pictures (vs. control images), they adopt American cultural practices, and consequently, able to manage the problem (Chiu, Morris, Hong, \& Menon, 2000; Fu et al., 2007). Thus, it is assumed that having more multicultural experience is negatively associated with the creative potential among individuals with the close-minded trait, or low levels of Openness to Experience. 


\subsection{Extroversion, Multicultural Experience, and Creativity}

Extroverted individuals described as persons who are socially adapted, and expressive. As a result, they are seeking for popularity, parties attended, dating variety, and exercise (Paunonen, 2003). Getting along with a variety of people brings familiarity with others perspectives and thoughts that may be unconventional and unheard and, as a result, influence on their cognitive organizations (Wilt \& Revelle, 2008). The combination of these experiences may lead to the formation of novel and useful solutions when they are living abroad undergoing the extensive multicultural experience. Despite the fact that the study by Feist (1998) claimed that individuals with the preference to be away from others, but with the mastery of expressing their ideas that others can understand and appreciate these attributions are highly creative, ascribing the introverted personality traits (Gardner, 2011; Tadmor, Galinsky, \& Maddux, 2012).

According to Kirton's Adaptive-Innovative Theory (1976), however, those with a high ability to socially adapt to other cultures prefer to "do things better" and innovators are people who prefer to "do things differently". In other words, adaptors crave to do things better; innovators seek out to do things differently. It highlights that the person who adopts better in the new cultural environment should be more creative than other individuals (Kirton, 2003). Accordingly, it is predicted that extroverted individuals would benefit from the multicultural experience of living abroad and the experience may promote their creative potential in finding the creative solution.

In sum, this study seeks to examine the interactive effect of multicultural experience and two aspects of Big Five Personality Traits, Openness to Experience and Extroversion, on the creative problem-solving ability. More specifically, the particular hypotheses of the current study are;

$H_{1}$ : Extensive multicultural experience would be positively associated with the enhanced creative potential among individuals with high level of Openness to Experience.

$\mathrm{H}_{2}$ : Extensive multicultural experience will be hampered the individuals' creative problem solving-ability when they are not open to experience.

$H_{3}$ : The multicultural experience enhances individuals' creative ability, among students with high levels of Openness and Extroversion personality traits.

\section{Method}

Data were gathered using a questionnaire set administrated in the main libraries at the Universiti Putra Malaysia (UPM). The questionnaires were designed to measure two aspects of Big Five Personality traits, Multicultural Experience and Desire, Creative Problem Solving and demographic profile (e.g. age, gender, marital status, educational levels, etc.). The study instructions and instruments were all in English.

\subsection{Participants}

A total of 102 full-time international students (64\% male, 35\% female) from UPM ranged from degree $(21.8 \%)$ to doctorate $(25.6 \%)$ were selected. The average age of participants was 
29.5 years $(\mathrm{SD}=6.60)$. The background information showed participants came from 27 different nations including Nigeria (20), Indonesia (11), Palestine (7), Yemen (6), China (6), Iran (5), Iraq (5), India (4), Pakistan (4), Jordan (4), Labia (4), Myanmar (2), Uganda (2), Gabon (2), Sudan (2), Somalia (2), Thailand (2), Zimbabwe (2), Sri Lanka (2), Gambia (2), Kazakhstan (2), Congo (1), Gambian (1), Cameron (1), Maldives (1) and Singapore (1).

\subsection{Measures}

Duncker candle problem is a cognitive performance test designed to measure the influence of cognitive bias that limits or prevent individuals from using objects only in the way they have been traditionally used, it has been used a measure of problem-solving capabilities (e.g., Gino \& Ariely, 2012; Maddux, Adam, \& Galinsky, 2010; Maddux \& Galinsky, 2009; Pink, 2011).

The test consisted of asking the participants to fix a lit candle on a wall made of cork board in such a way that the candle wax does not drip onto the table below. The participants were presented by a candle, a box of matches and a box full of thumbtacks, to complete the task through being painted or written. A simple solution is to empty the box of thumbtacks, place the candle in the box using tasks. Because of the inconsistency of the solution with the preexisting associations and expectations participants cognitive bias will prevent them from using the box full of thumbtacks as a 'candle holder' that could prevent the wax from dripping onto the table (Glucksberg \& Weisberg, 1966; Maddux \& Galinsky, 2009); the box contain the candle to the wall using the thumbtacks and light the candle with the match.

Extroversion and Openness to Experience Traits were measured using 40 items of from the Big Five Aspects Scale (BFAS; DeYoung, Quilty, \& Peterson, 2007). Items were rated on a 5-point scale ranging from 0 (Never or rarely true) to 4 (Very often true or always true). The BFAS assesses two separate aspects of each Big Five dimension. Accordingly, Extroversion consists of "enthusiasm" and "assertiveness" traits for 20-item scale and a 20-item, and Openness to Experience combines "intellect" and "Openness". After reversing the negative scores of each scale items, the scale showed a high reliability $(\alpha=.75$ for Openness to Experience, $\alpha=.77$ for Extroversion). As a measure of the wide aspects, the BFAS has validated against standard Big Five instruments such as the BFI (John \& Srivastava, 1999) and the NEO PI-R (Costa \& McCrae, 1992) with an average uncorrected correlation of $r$ $=.76$. The scale also shows internal (mean $\mathrm{r}=.83$ ) and test-rest (mean $\mathrm{r}=.81$ ) reliability.

Multicultural Experience Questionnaire was used to measure the multicultural experience (MEQ; Narvaez \& Hill, 2010). The MEQ is a 15-item, two-factor self-report scale developed for measuring individuals' multicultural experience and attitudes. The MEQ uses the term "culture" to refer to experience with a wide variety of groups, specifically, various ethnic minorities, immigrants, resident aliens, women, men, and homosexuals, as well as a range of political and religious orientations. The questionnaire has two main subscales on a 5-Likert scale. The "multicultural experience" subscale (9 items, $\alpha=.69)$ represents the number of multicultural experience a person has had and the "multicultural desire" subscale (6 items, $\alpha=.70$ ) represents the person's efforts or desires to increase their multicultural experience. 


\section{Result}

The responses to the Duncker candle problem are directed into two groups of correct or incorrect. In order to keep the integrity of the study and to effort duplication of the originality of test, the responses that solve the problem in an innovative way are scored as incorrect. As an overall, $31 \%$ of the students solve the problem correctly. Table 1 illustrates the mean, standard deviation and range of variables.

The mean score of multicultural experience as $30.86(\mathrm{SD}=4.65)$, near to scale midpoint. The mean of desire to increase their multicultural experience is 22.91 ( $\mathrm{SD}=5.43)$. Open to Experience's mean is 50.13 ( $\mathrm{SD}=8.5$ ) and the mean of Extroversion is 48.02 ( $\mathrm{SD}=8.48$ ); both are above the scale midpoint. As the respondents are international students, it is expected that they express the higher level of multicultural experience, multicultural desire and Openness to Experience.

Table 1. Descriptive analysis of variables and instruments' reliability

\begin{tabular}{lccccc}
\hline & Mean & St. Deviation & No. Items & Alpha & Range \\
\hline Duncker candle problem & --- & --- & 1 & --- & $0-1$ \\
Openness to Experience & 50.98 & 8.78 & 20 & .75 & $34-69$ \\
Intellectual & 25.68 & 6.06 & 10 & .70 & $15-39$ \\
Openness & 24.52 & 3.50 & 10 & .67 & $16-39$ \\
Extroversion & 49.47 & 8.40 & 20 & .77 & $33-68$ \\
Enthusiastic & 24.29 & 5.71 & 10 & .71 & $9-38$ \\
Assertiveness & 25.22 & 4.60 & 10 & .70 & $16-40$ \\
Multicultural Experience & 31.08 & 4.96 & 9 & .69 & $16-41$ \\
Multicultural Desire & 23.31 & 4.34 & 6 & .70 & $11-30$ \\
\hline
\end{tabular}

Table 2. Multicultural experience relation to problem solving (Step 2)

\begin{tabular}{lcccc}
\hline & B & S.E. & Wald & Sig. \\
\hline Gender(Male $=1)$ & -1.985 & .771 & 6.628 & .010 \\
Age & -.050 & .064 & .625 & .429 \\
Nationality (1=South Asian) & -.184 & .235 & .615 & .433 \\
Educational Status (Bachelor=1) & -.553 & .615 & .810 & .368 \\
Years living in Malaysia & .008 & .017 & .216 & .642 \\
Extroversion & .051 & .042 & 1.504 & .220 \\
Openness to Experience & .122 & .043 & 8.096 & .004 \\
Multicultural Experience & .111 & .078 & 2.056 & .152 \\
Multicultural Desire & -.121 & .089 & 1.836 & .175 \\
\hline Constant & -4.184 & 3.213 & 1.695 & .193 \\
\hline
\end{tabular}

Note, 1. Nationality ( $1=$ South Asia, South East Asia $=2$, East Asia $=3$, Middle East $=4 \&$ Africa $=5), 2$. Educational (1= Bachelor, $2=$ Master, $3=$ Doctorate), 3. Nagelkerke $\mathrm{R}^{2}=.44$.

The association between the independent variables and the creativity task among the international students was assessed using a hierarchical binary logistic regression, with gender, age, nationality, educational levels, years living in the host country entered on the first block as control variables, and with multicultural experience, multicultural desire and 
two personality traits entered on the second block. The insignificant result of Hosmer and Lemeshow Test shows that the study model is fit $\left[\chi^{2}(\mathrm{DF}=8)=14.65, p=.08\right]$. After controlling the effect of age, gender, nationality, year living in Malaysia and education levels $\left(\mathrm{R}^{2}=.17\right)$, the results (Table 2) show only Openness to Experience significantly predicts the enhanced problem-solving ability $\left(\mathrm{B}=.12, p=.004, \mathrm{R}^{2}=.44\right)$, among the variables. Multicultural Experience and Desire are not predictors of the creative solution.

In order to demonstrate that the multicultural experience is positive among individuals with high Openness to Experience, the interaction between Openness to Experience $x$ Multicultural experience and the creative solution was examined using a hierarchical, binary logistic regression. After controlling the main effects of Extroversion as well as other control variables, including age, gender, nationality, years in Malaysia $\left(\mathrm{R}^{2}=.32\right)$, the interaction term was the significant predictor of the creative solution $(\mathrm{B}=.002, \mathrm{~S} . \mathrm{E}=.001$, Wald $=7.78, p=.005$, $\mathrm{R}^{2}=.42$ ). This makes it clear that individuals with higher levels of Openness show the enhanced problem-solving ability. To illustrate that individuals with low and high levels of Openness have a reversal association with the creative solution, a subgroup analysis was conducted dichotomizing the Openness to Experience into low and high groups by the midpoint split. Consistent with the first and second hypotheses, the bottom half of Table 3 shows that the multicultural experience was the only predictor of the creative solution when students are highly open to experience. In contrast, the multicultural experience is negatively associated with the creative solution among individuals with low levels of Openness to Experience $(\mathrm{B}=-.05)$. This finding lends well support for hypothesis 2. However, since Extroversion was not the predictor of problem solution, it shows Extroversion has no effect on solving the problem correctly, rejecting the third hypothesis.

Table 3. Multicultural experience and openness to experience interaction in relation to the problem solving (Step 2)

\begin{tabular}{|c|c|c|c|c|c|c|}
\hline & & & $\mathrm{B}$ & S.E. & Wald & Sig. \\
\hline Gender(Male=1) & & & -1.870 & .754 & 6.157 & .013 \\
\hline Age & & & -.060 & .063 & .899 & .343 \\
\hline Nationality & & & -.217 & .233 & .865 & .352 \\
\hline Educational levels & & & -.384 & .626 & .376 & .540 \\
\hline Years in Malaysia & & & .004 & .016 & .056 & .812 \\
\hline Extroversion & & & .051 & .040 & 1.628 & .202 \\
\hline Openness $\times \mathrm{ME}$ & & & .002 & .001 & 7.783 & .005 \\
\hline Constant & & & -1.124 & 2.869 & .154 & .695 \\
\hline \multicolumn{7}{|c|}{ Openness Subgroup Coefficients for Relation between Multicultural Experience and Creative Solutio } \\
\hline & $\begin{array}{c}\text { Openness to Experience } \\
\text { groups }\end{array}$ & $\mathrm{N}$ & $\mathrm{B}$ & S.E. & Wald & Sig. \\
\hline Multicultural & Low Group & 13 & -.018 & .242 & .006 & .941 \\
\hline Experience & High Group & 89 & .114 & .049 & 5.461 & .019 \\
\hline
\end{tabular}

Note. 1. Nationality (1= South Asia, South East Asia= 2, East Asia= 3, Middle East $=4 \&$ Africa= 5), 2. Educational (1= Bachelor, 2=Master, 3= Doctorate), 3. Spilt was obtained by scale midpoint, 4. Effect of gender was controlled in sub group analysis. 


\section{Discussion}

Although previous studies have shown that the multicultural experience is only beneficial for individuals with higher Openness to Experience in order to foster their creative potential $(\mathrm{Fu}$ et al., 2007; Leung \& Chiu, 2008), the role of Extroversion personality is predominantly ignored. This aspect of personality is demonstrated to be strongly associated with multicultural experience and creativity (Feist, 1998; Wilt \& Revelle, 2008). To develop this association, the current study aims to explore the association between multicultural experience and creative problem-solving ability with the interactive effect of the Openness to Experience as well as the Extroversion using a quantitative method among a diverse sample of international students. The primary results indicate Openness to Experience is the robust predictor of the creative solution. In contrast, multicultural desire and experience are not associated with the task solution. Therefore, it is initially concluded that the problem-solving ability would be promoted when students are open to experience.

Through the interactive effects of Openness to Experience and multicultural experience on the creative solution, it is demonstrated that the multicultural experience strongly predicts the creative potential when students are highly open to experience. Moreover, findings show that multicultural experience declined individuals' creative ability when they are not open to experience. This result lends well support to studies that theorize the association between multicultural experiences and highly open individuals (Hong et al., 2007; Leung \& Chiu, 2008).

According to Leung and Chiu (2008), the reason behind this outcome is that once people with low psychologically prepare for new experience, enthusiastically or desirably, move into unfamiliar settings, they may find experience with foreign cultures overwhelming, stressful and shocking. To manage their stressful experience, they may reject new ideas from other cultures and fall back on own culturally accessible ideas and, consequently, show the decline in creative potential (Chiu et al., 2000; Fu et al., 2007). Similarly, Runco (2004) argues that the interaction of personal and contextual factors may be shocking and distressing. Thus, individuals would reject novel and inaccessible ideas to reduce the culture shock and, consequently, this rejection hampered their creative ability (Rhodes, 1987). Furthermore, because Extroversion and multicultural experience were not the predictors of the problem solution, it is concluded that Extroversion has no effect on enhancement of individuals' creative problem-solving ability.

In conclusion, the study findings empirically illustrate that multicultural experience is beneficial for students to enhance their creative potential when they are not highly open to experience. Moreover, multicultural experience would have negative effects on students' problem-solving ability when they are not open to experience. Thus, a learning environment that affords multicultural experience and promotes openness to experience would be most conducive to the development of the creative potential.

\section{References}

Amabile, T. M. (1996). Creativity in context: Update to the social psychology of creativity. Boulder, CO: West-view Press. 
Benet-Martínez, V., Lee, F., \& Leu, J. (2006). Biculturalism and cognitive complexity expertise in cultural representations. Journal of Cross-Cultural Psychology, 37(4), 386-407.

Chao, M. C., Chen, J., Roisman, G. I., \& Hong, Y. (2007). Essentializing race: Implications for bicultural individuals' cognition and physiological reactivity. Psychological Science, 18(4), 341-348.

Chiu, C., \& Hong, Y. (2005). Cultural competence: Dynamic processes. In A. Elliot \& C. S. Dweck (Eds.), Handbook of Motivation and Competence (pp. 489-505). NY: Guilford Press.

Chiu, C., Morris, M., Hong, Y., \& Menon, T. (2000). Motivated cultural cognition: The impact of implicit cultural theories on dispositional attribution varies as a function of need for closure. Journal of Personality and Social Psychology, 2(78), 247-259.

Costa, P. T., \& McCrae, R. R. (1992). Normal personality assessment in clinical practice: the NEO Personality Inventory. Psychological Assessment, 4(1), 5.

Costa, T., \& McCrae, R. (1992). Four ways five factors are basic. Personality and Individual Differences, 13(6), 653-665.

DeYoung, C. G., Quilty, L. C., \& Peterson, J. B. (2007). Between facets and domains: 10 aspects of the Big Five. Journal of Personality and Social Psychology, 93(5), 880.

Feist, G. J. (1998). A meta-analysis of personality in scientific and artistic creativity. Personality and Social Psychology Review, 2(4), 290-309.

Fu, H., Morris, M., Lee, S., Chao, M., Chiu, C., \& Hong, Y. (2007). Epistemic motives and cultural conformity: Need for closure, culture, and context as determinants of conflict judgments. Journal of Personality and Social Psychology, 51(92), 191-207.

Gino, F., \& Ariely, D. (2012). The dark side of creativity: original thinkers can be more dishonest. Journal of Personality and Social Psychology, 102(3), 445-457.

Glucksberg, S., \& Weisberg, R. W. (1966). Verbal behavior and problem solving: Some effects of labeling in a functional fixedness problem. Journal of Experimental Psychology, 71(5), 659-681.

Hong, Y., Morris, M., Chiu, C., \& Benet-Martinez, V. (2000). Multicultural minds: A dynamic constructivist approach to culture and cognition. American Psychologist, 55(7), 709.

Hong, Y., Wan, C., No, S., \& Chiu, C. (2007). Multicultural identities. In S. Kitayama \& D. Cohen (Eds.), Handbook of Cultural Psychology (pp. 323-345). New York: Guilford.

Gardner, H. (2011). Creating minds: An anatomy of creativity seen through the lives of Freud, Einstein, Picasso, Stravinsky, Eliot, Graham, and Ghandi. The US: Basic Books (AZ).

Ip, G., Chen, J., \& Chiu, C. (2006). The relationship of promotion focus, need for cognitive closure, and categorical accessibility in American and Hong Kong Chinese university students. Journal of Creative Behavior, 40(3), 201-215.

John, O. P., \& Srivastava, S. (1999). The Big Five trait taxonomy: History, measurement, and 
theoretical perspectives. In L. A. Pervin, \& O. P. John (Eds.), Handbook of personality: Theory and Research (pp. 102-138). New York: Guilford Press

Kirton, M. (1976). Adaptors and innovators: A description and measure. Journal of applied psychology, 61(5), 622.

Kirton, M.J. (2003), Adaption-Innovation: In the context of diversity and change. London, UK: Routledge.

Leung, A. K., Maddux, W. W., Galinsky, A. D., \& Chiu, C. (2008). Multicultural experience enhances creativity: The when and how. American Psychologist, 63(3), 169.

Leung, A., \& Chiu, C. (2008). Interactive effects of multicultural experience and openness to experience on creative potential. Creativity Research Journal, 20(4), 376-382.

Leung, A., Maddux, W., Galinsky, A., \& Chiu, C. (2008). Multicultural experience enhances creativity: The when and how. American Psychologist, 63(3), 169.

Maddux, W., \& Galinsky, A. (2009). Cultural borders and mental barriers: The relationship between living abroad and creativity. Journal of Personality and Social Psychology, 96(5), 1047.

Maddux, W., Adam, H., \& Galinsky, A. (2010). When in Rome... Learn why the Romans do what they do: How multicultural learning experiences facilitate creativity. Personality and Social Psychology Bulletin, 36(6), 731-741.

McCrae, R. R., \& Costa, P. T., Jr. (2008). Empirical and theoretical status of the Five-Factor Model of personality traits. In G. Boyle, G. Matthews, \& D. Saklofske (Eds.), Handbook of Personality and Testing. Thousand Oaks, CA: Sage.

McCrae, R., \& Costa, P. (1987). Validation of the five-factor model of personality across instruments and observers. Journal of Personality and Social Psychology, 52(1), 81-90.

McCrae, R., \& Costa, P. (1997). Personality trait structure as a human universal. American Psychologist, 52(5), 509.

Narvaez, D., \& Hill, P. L. (2010). The relation of multicultural experience to moral judgment and mindsets. Journal of Diversity in Higher Education, 3(1), 43.

Paunonen, S. V. (2003). Big Five factors of personality and replicated predictions of behavior. Journal of Personality and Social Psychology, 84(2), 411.

Pink, D, H. (2011). Drive: The surprising truth about what motivates us: Riverhead Books, NY.

Rhodes, M. (1987). An analysis of creativity. Buffalo, NY: Bearly Limited.

Runco, M. A. (2004). Creativity. Annual Review of Psychology, 2(2), 93-96.

Sternberg, R. J., \& O’Hara, L. A. (1999). Creativity and Intelligence. In R. J. Sternberg (Ed.), Handbook of Creativity (pp. 251-272). Cambridge, England: Cambridge University Press. 
Tadmor, C. T., Galinsky, A. D., \& Maddux, W. W. (2012). Getting the most out of living abroad: Biculturalism and integrative complexity as key drivers of creative and professional success. Journal of Personality and Social Psychology, 103(3), 520-542.

Wilt, J., \&amp; Revelle, W. (2008). Extroversion. In M. Leary \& R. Hoyle (Eds.), Handbook of Individual Differences in Social Behavior. Guilford: The US.

\section{Copyright Disclaimer}

Copyright for this article is retained by the author(s), with first publication rights granted to the journal.

This is an open-access article distributed under the terms and conditions of the Creative Commons Attribution license (http://creativecommons.org/licenses/by/3.0/). 